\title{
Thermal Expansion Behavior of Nonoriented Polypropylene/Clay Composites
}

\author{
Fares D. Alsewailem ${ }^{1}$ and Metin Tanoglu ${ }^{2}$ \\ ${ }^{1}$ Petrochemicals Research Institute, King Abdulaziz City for Science and Technology (KACST), P.O. Box 6086, \\ Riyadh 11442, Saudi Arabia \\ ${ }^{2}$ Mechanical Engineering Department, Izmir Institute of Technology, Gulbahce Koyu, 35430 Urla, Turkey
}

Correspondence should be addressed to Fares D. Alsewailem; fsewailm@kacst.edu.sa

Received 11 November 2013; Accepted 24 December 2013; Published 3 February 2014

Academic Editors: A. V. Popov and A. Voronov

Copyright (c) 2014 F. D. Alsewailem and M. Tanoglu. This is an open access article distributed under the Creative Commons Attribution License, which permits unrestricted use, distribution, and reproduction in any medium, provided the original work is properly cited.

\begin{abstract}
Linear thermal expansion coefficient (LTEC) was measured for compression molding samples of polypropylene (PP)/clay composites with clay loading of 0 to $7 \mathrm{wt} \%$. Composites were prepared by internal batch mixer and specimens were prepared by compression molding. These processing methods are not anticipated to have a preference for orientation; therefore effect of anisotropy was minimal. The LTEC was measured along three different faces of the compression molding sheets, parallel to compression direction S1 and perpendicular to compression directions S2 and S3. The LTEC for neat PP measured by current research, $1 \times 10^{-4} \mathrm{~mm} / \mathrm{mm} /{ }^{\circ} \mathrm{C}$, was not found to be altered by direction of the measurements. Similar behavior was observed with composites having very moderate clay content, that is, $5 \mathrm{wt} \%$. An interesting finding by current study was that incorporating clay particles into the PP matrix led to better shrinkage or contraction behavior of the samples prepared by compression molding.
\end{abstract}

\section{Introduction}

Polypropylene (PP) is a versatile polyolefin that finds a strong demand in some of the advanced applications such as automotive industry. What makes PP a good candidate for such advanced applications is the excellent chemical and mechanical properties due to its superior crystallinity nature. PP is a highly crystalline polyolefin with relatively higher melting and softening temperature compared to other commodity vinyl polymers such as polyethylene (PE) and polystyrene (PS). Some of the interior parts of an automotive may be made of PP. Recently, glass fiber reinforced PP was introduced to be used in the under-the-hood parts in automotive. Despite this versatility in applications for the $\mathrm{PP}$, this polymer suffers from dimensional instability due to high linear thermal expansion coefficient (LTEC). Neat PP has different values of LTEC depending on the orientation of crystalline chain domain [1]. Draw ratio and temperature are the main factors that may affect the LTEC of oriented PP. In general, LTEC is higher for the segment that is perpendicular to the draw direction, while for the segment that is parallel to the draw direction, less values of LTEC may be observed [1]. Jawad et al. [2] have postulated that internal shrinkage stresses may play a major role on the magnitude of LTEC for the oriented PP that was subject to annealing processing. Nonannealed PP samples may exhibit a negative value of LTEC in the axial direction (i.e., parallel to draw direction) as a response to the positive LTEC in the transverse direction (i.e., perpendicular to the draw direction) [3]. Anisotropy in LTEC was also observed in PP blends with elastomeric materials [4]. LTEC for injection molded samples containing $30 \mathrm{vol} \%$ of polyethylene-co-octene blended with isotactic PP had higher values of LTEC in the direction normal to flow, and it decreased in the flow direction; however at higher viscosity ratios of PECO to PP the anisotropy became minimum [4]. Low thermal expansion coefficient materials such as inorganic fillers and fibers may be utilized to produce thermally dimensional stable composite systems based on PP matrix [5-7]. Incorporation of glass fibers into PP matrix was seen to reduce LTEC of the resulted composite; however no 
significant change in LTEC has been observed when varying the fiber length [5]. Hine et al. has reported that addition of $10 \%$ carbon nanofibers to PP tended to cause a $30 \%$ reduction in LTEC [6]. Despite the promising results given by previous two papers $[5,6]$, the issue of anisotropy was not given a proper attention. Kalaitzidou et al. [7] have investigated thermal expansion property of PP modified by carbon black, carbon fibers, and graphite nanoplatelets. They have shown that incorporating $3 \mathrm{vol} \%$ of the previously mentioned carbon fillers and fibers tended to decrease the LTEC in the flow direction of injection molded samples of the composites, while in the transverse direction, there was no significant reduction. The reduction in LTEC was more pronounced when the temperature was well above the glass transition temperature, $T_{g}$ of PP. LTEC for neat PP may increase twofold when it passes its $T_{g}$ [7]. In the last few years, some studies have been published on thermal expansion properties of PP modified by clay materials [8-11]. Most of these studies have concluded that LTEC for composites containing clay and PP tended to decrease as clay loading increased in the flow and transverse to flow direction of the injection molding samples, and the normal to flow direction LTEC increased slightly upon increasing clay loading [9-11]. No logical rational for the reduction in LTEC in the normal direction was given by such studies. Krump et al. [8] have attributed the increase in LTEC for PP/clay nanocomposites as clay content increased to the degree of crystallinity of the resulted composites. As clay content in the composites increased, heat of fusion which implies the degree of crystallinity decreased and as a result LTEC increased [8].

In our study we tried to relate the processing nature to the extent of thermal expansion of $\mathrm{PP} /$ clay composites. In other words we intended to minimize the influence of orientation on the magnitude of LTEC by changing the process type. The reader may realize that most of the studies conducted on thermal expansion coefficient of either neat PP or PP modified by inorganic fillers and fibers have used samples taken from injection molding specimens where the orientation effect is very high. Here we used compression molding as a means to prepare our samples for the LTEC tests in order to have less oriented chain segments. We would like to investigate the anisotropy nature of LTEC for unoriented $\mathrm{PP} /$ clay composites.

\section{Experimental}

2.1. Materials Used. Polymer matrix used in this study was a homopolymer PP (MH418), a courtesy of PETKIM Petrochemical, Turkey. Polypropylene grafted with malice anhydride PP-g-MA (Fusabond M613-05) was used as a coupling agent for PP/clay composite systems. The clay used in this study was as received Turkish Montmorillonite with no surface modification or treatment.

2.2. Composites Preparation. The $\mathrm{PP} /$ clay was prepared by a Haake batch mixer (Polylab) at $190^{\circ} \mathrm{C}$ and $80 \mathrm{rpm}$. After $2 \mathrm{~min}$ of melting the PP, PP-g-MA was added to the PP and let melt mix for another $2 \mathrm{~min}$. After that, clay in the amounts ranging

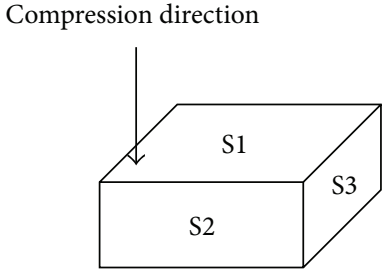

FIGURE 1: Schematic of TMA specimens showing the three surfaces where LTEC was measured (S1 parallel to compression direction and S2 and S3 perpendicular to compression direction).

from 1 to 7 wt.\% was added into the mixer and continued to mix for $7 \mathrm{~min}$. The ratio of clay to PP-g-MA was $1: 3$. The blended samples were collected and left for cooling. After cooling, the blends were pressed into $100 \mathrm{~mm} \times 100 \mathrm{~mm}$ samples having a thickness of $2 \mathrm{~mm}$ using a hot press (CarverHydrolic Press 25 ton) at $190^{\circ} \mathrm{C}$.

2.3. Characterization of the Composites. XRD was used to determine the characteristic peaks of the prepared composites. Scanning electron microscope (FEI, model NNL 200) was used to investigate the fracture surfaces of the composites. Thermogravimetric (PerkinElmer TGA-7) was used to determine the exact loading of the clay within the PP matrix and to assess the thermal stability of the composites.

2.4. Thermal Expansion Measurements. Small parallelogram pieces with the dimension of $2 \mathrm{~mm} \times 3 \mathrm{~mm} \times 3 \mathrm{~mm}$ were cut of the compression molding sheets as shown in Figure 1. Those specimens were used to measure the LTEC of the composites by a thermomechanical analyzer (PerkinElmer TMA-7) using expansion probe with zero force loading. Each specimen was tested in three different directions, parallel to compression direction S1 and perpendicular to compression directions S2 and S3 as shown in Figure 1. Samples were heated twice from $25^{\circ} \mathrm{C}$ to $60^{\circ} \mathrm{C}$ at a heating rate of $5^{\circ} \mathrm{C} / \mathrm{min}$. This action will erase any effect associated with thermal and stress histories (e.g., frozen stresses etc.). The second heat scans were considered for LTEC measurements.

\section{Results and Discussions}

3.1. Characterization of the Prepared PP/Clay Composites. Figure 2 shows the broad XRD spectra of the PP/clay nanocomposites at various amounts of clay particles. Figure 3 shows a zoom in graph of the intensity of peaks at $2 \theta$ in the range of 8.5 to 9 . It is evident from Figure 3 that as clay content increased, the intensity of the peak at $2 \theta \sim 9$ increased as well which implies the presence of clay platelets within the PP matrix. Figure 4 shows that the peak intensity at $2 \theta \sim 14$ is suppressed to greater extent upon increasing clay content, that is, $3-5 \mathrm{wt} \%$. For the neat PP, that is, at $0 \mathrm{wt} \%$ clay loading, the intensity of the peak at $2 \theta \sim 14$ is more pronounced. Needless to say that the suppression of peak intensities upon increasing clay content is due to clay interaction with PP matrix. The TGA measurement which 

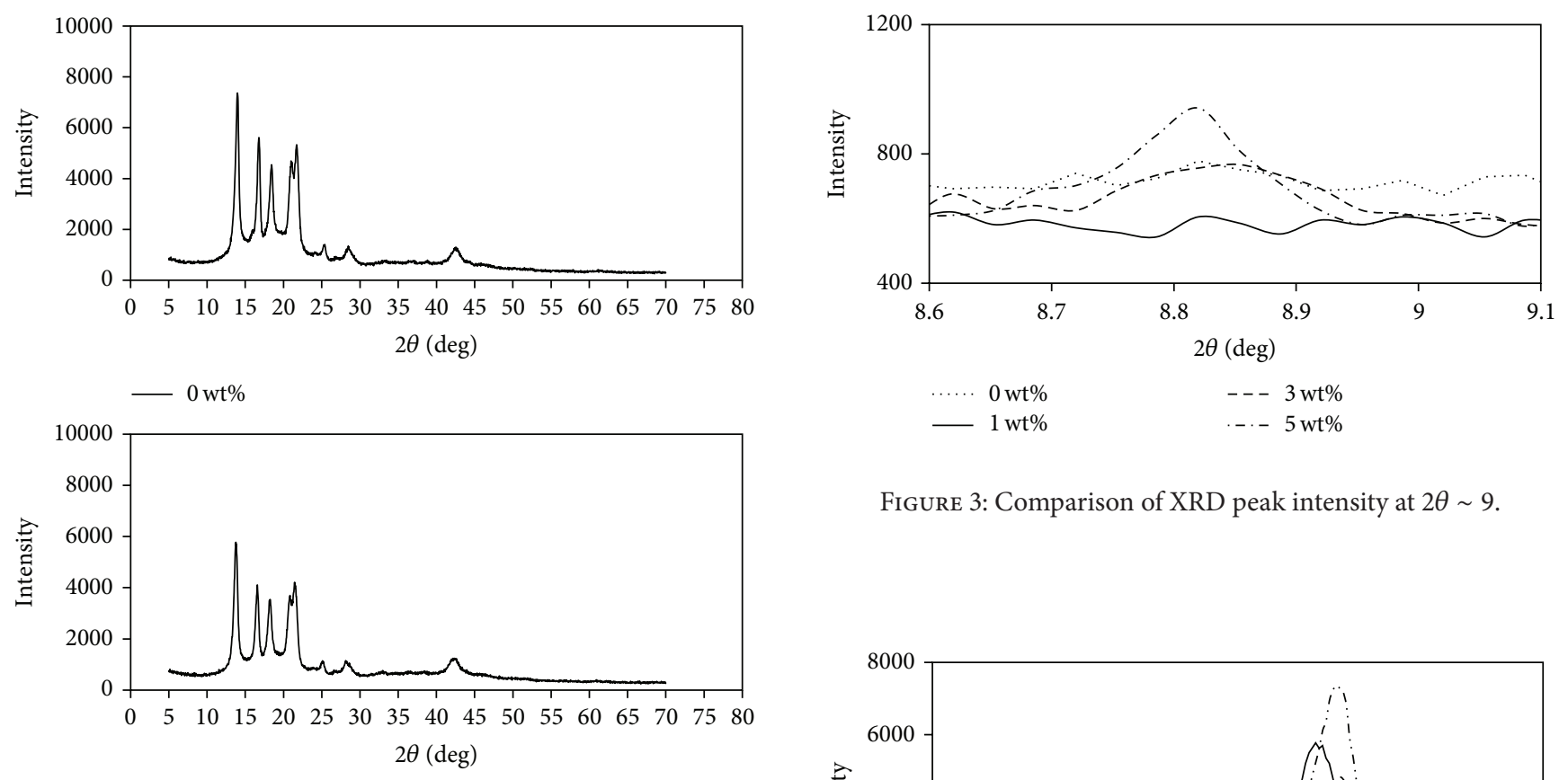

FIGURE 3: Comparison of XRD peak intensity at $2 \theta \sim 9$.
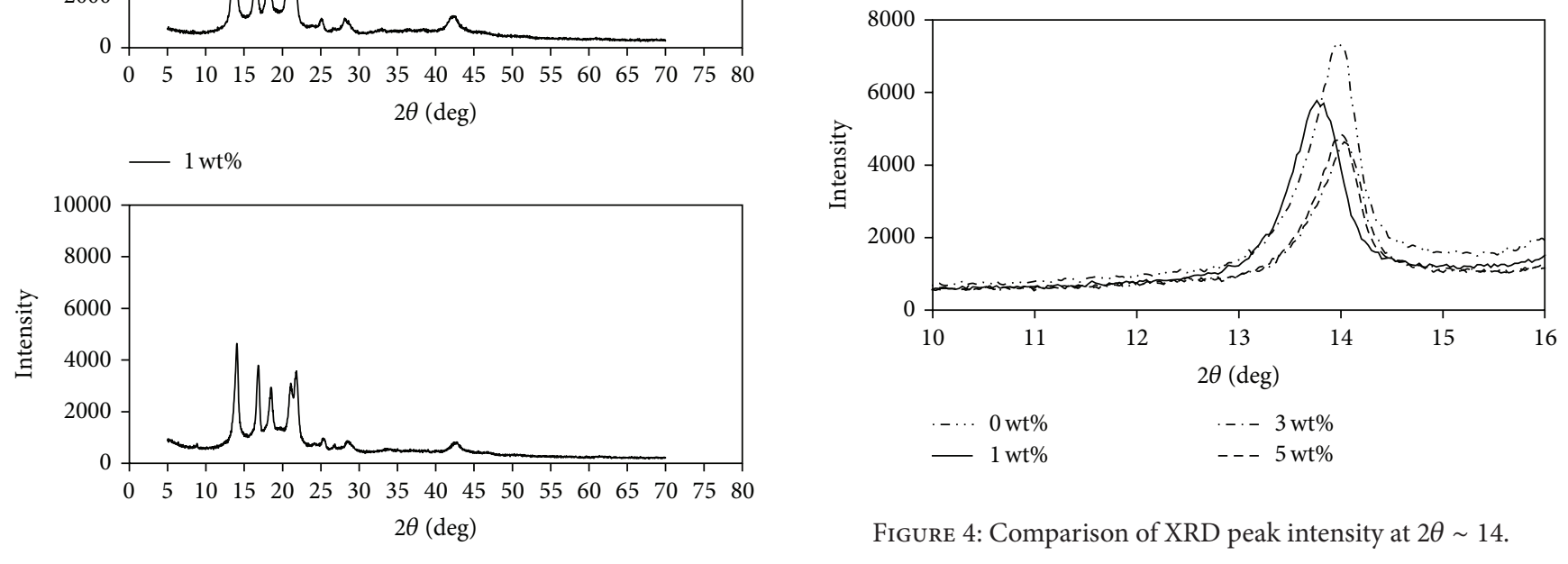

FIGURE 4: Comparison of XRD peak intensity at $2 \theta \sim 14$.

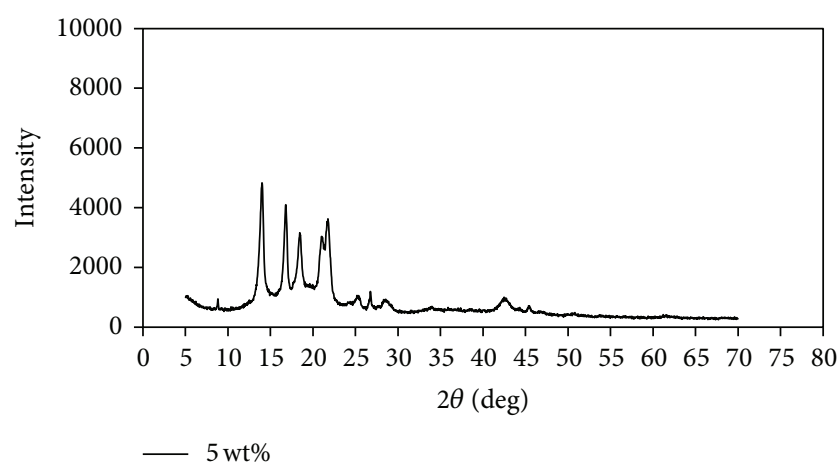

FIGURE 2: XRD spectra of PP/clay composites at various clay contents.

is given in Figure 5 confirmed the contents of clay when performing the melt mixing in the batch mixer. It is also seen from Figure 5 that incorporating clay platelets within PP matrix tended to increase thermal stability of the resulted composites, and this was more pronounced at higher clay loading, that is, $7 \mathrm{wt} \%$. The appearance of the compression molded samples may give a clear indication regarding the dimensional stability and shrinkage behavior of the prepared

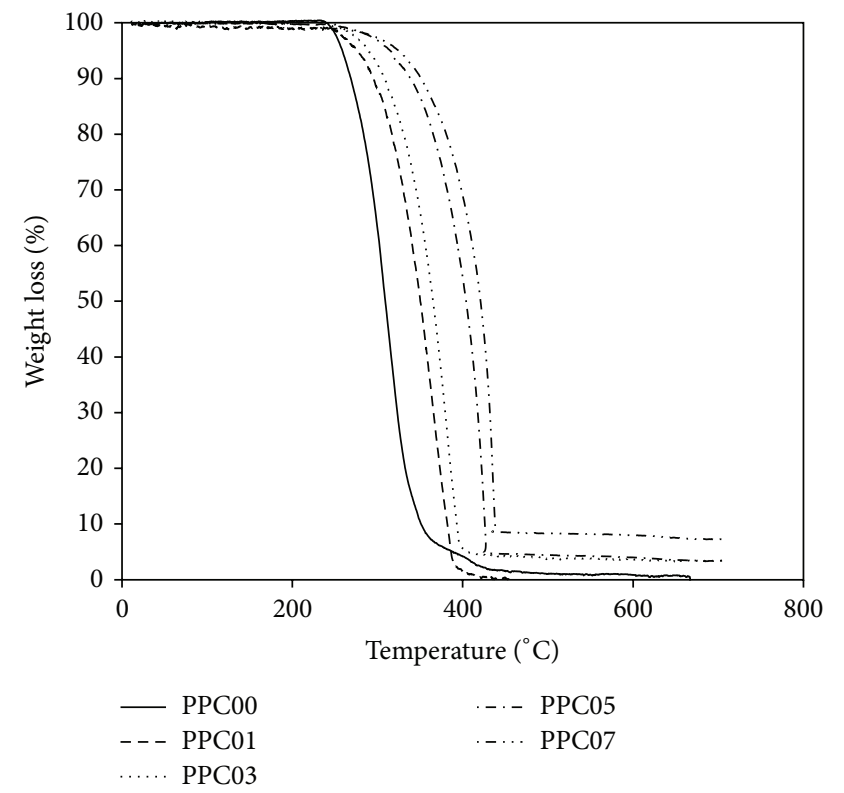

FIgURE 5: TGA curves for the prepared PP/clay composites. 


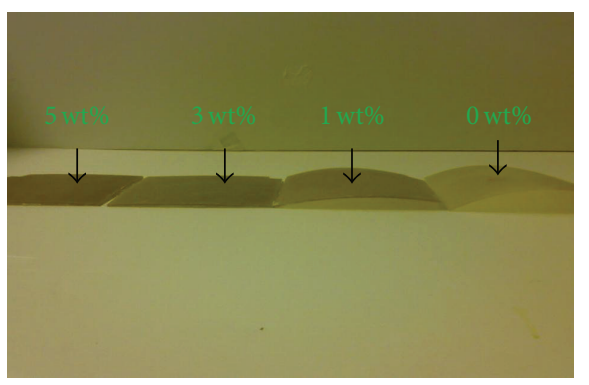

FIGURE 6: Molded samples at various clay content after natural cooling.

composites, or in other words the influence of the clay phase on the shrinkage behavior of $\mathrm{PP} /$ clay composites as shown by Figure 6. It can be seen from Figure 6 that when the neat PP or the PP with less clay content, that is, $1 \mathrm{wt} \%$, was taken out of the hot press at $40^{\circ} \mathrm{C}$ and let to be cooled naturally, that is, in the open air, they tended to bend. In the contrast, the composites with higher percent of clay, that is, 3 and $5 \mathrm{wt} \%$, had shown no sign of curvature. This may be attributed to high shrinkage value of the neat PP molecular chains. Here one may conclude that incorporating clay particles within the neat PP can suppress the shrinkage of molded articles upon heating/cooling cycles during the processing by compression molding technique. Specimens were cryogenic cut out of the compression molding sheets in the three directions as specified in the experimental section and Figure 1 and then the fracture surfaces were examined by the SEM. The SEM micrographs of the fracture surfaces S1, S2, and S3 of the $\mathrm{PP} /$ clay composites at various clay loading are shown in Figure 7. The SEM micrographs reveal that at fairly high magnification, that is, 5000x, the morphology was fine with no sign for clay particles coalescence or clustering and in fact the domains of clay platelets started to show up clearly at higher clay content, $5 \mathrm{wt} \%$, as indicated in Figure $7(\mathrm{~d})$. This observation is supported by XRD analysis given above which may lead us to assume that exfoliation of clay platelets has taken place at the nanoscale. Furthermore no sign of domain orientation was significantly observed from the SEM micrographs at the three different direction of the specimens, that is, S1, S2, and S3.

\subsection{Thermal Expansion Behaviors of the Prepared PP/Clay} Composites. The increase in specimen length relative to its original length, that is, $\Delta L / L_{0}$, was plotted versus temperature for the three designated surfaces, S1, S2, and S3, as shown in Figure 8. These measurements were performed by the TMA in the temperature range between 25 and $60^{\circ} \mathrm{C}$ using expansion mode with zero force loading. The temperature range chosen was reasonable and realistic to monitor thermal elongation or expansion of the prepared composites for outdoor application such as in automotive especially in the countries with harsh weather during summer season. The slopes of the lines in Figure 8 which give the LTEC values for all the composites were calculated and summarized in Table 1. The LTEC, that is, $\left(\Delta L / L_{0}\right) / \Delta T$, values given in Table 1 were
TABLE 1: LTEC values at the three designated surfaces; S1, S2, and S3 for the PP/clay composites at various clay contents.

\begin{tabular}{lcccc}
\hline Clay wt $\%$ & Surface & $\begin{array}{c}\mathrm{LTEC} \times 10^{-4} \\
\left(\mathrm{~mm} / \mathrm{mm} /{ }^{\circ} \mathrm{C}\right)\end{array}$ & $\begin{array}{c}\left(\Delta L / L_{0} \text { at } 0^{\circ} \mathrm{C}\right), \\
\text { absolute values }\end{array}$ & $R 2$ \\
\hline 0 & $\mathrm{~S} 1$ & 1 & 25 & 0.9995 \\
0 & $\mathrm{~S} 2$ & 1 & 29 & 0.9949 \\
0 & $\mathrm{~S} 3$ & 1 & 33 & 0.9992 \\
1 & $\mathrm{~S} 1$ & 2 & 40 & 0.9963 \\
1 & $\mathrm{~S} 2$ & 1 & 27 & 0.9996 \\
1 & $\mathrm{~S} 3$ & 1 & 27 & 0.9998 \\
3 & $\mathrm{~S} 1$ & 4 & 70 & 0.9973 \\
3 & $\mathrm{~S} 2$ & 1 & 13 & 0.9933 \\
3 & $\mathrm{~S} 3$ & 1 & 14 & 0.9982 \\
5 & $\mathrm{~S} 1$ & 1 & 32 & 0.9981 \\
5 & $\mathrm{~S} 2$ & 1 & 10 & 0.9996 \\
5 & $\mathrm{~S} 3$ & 1 & 16 & 0.9997 \\
7 & $\mathrm{~S} 1$ & 2 & 31 & 0.9983 \\
7 & $\mathrm{~S} 2$ & 2 & 25 & 0.9393 \\
7 & $\mathrm{~S} 3$ & 0.8 & 16 & 0.9968 \\
\hline
\end{tabular}

plotted against clay loading as shown in Figure 9. Here one can see the effect of clay loading on the LTEC of the PP/clay composite system for the compression molding samples in the directions parallel and perpendicular to compression direction. Figure 9 indicates that for the composites with $0 \mathrm{wt} \%$ clay content, that is, neat PP, the LTEC value remains unchanged regardless of surface direction. Here, our finding contrasts with other studies conducted in the past for highly oriented either drawn films [2-4] or injection molding samples [9-11] where the LTEC value of PP was seen to change with direction. Therefore, one may confidently presume that the anisotropy of LTEC in very low oriented compression molding articles of neat PP does not exist. It is also seen from Figure 9 that with the exception of higher clay loading, greater than $7 \mathrm{wt} \%$, increasing clay loading does not alter the LTEC in the perpendicular directions, that is, $\mathrm{S} 2$ and S3, while in the compression direction, that is, S1, the LTEC increases significantly and reaches maximum value at clay content of $3 \mathrm{wt} \%$ and then decreases sharply at $5 \mathrm{wt} \%$. Others [9-11] have shown that LTEC of $\mathrm{PP} /$ clay composites prepared by injection molding technique tended to decrease upon increasing clay content in the directions parallel and transverse to the flow injection direction, while it increased in the normal direction. The authors [11] postulated that the cause of increase in LTEC in the direction normal to the flow was the reduction in the LTEC in both flow and transverse directions. Here, the increase in LTEC values in the S1 direction cannot be offset by unchanged or the slight increase or decrease in the LTEC values in the S2 and S3 directions. The absolute values of the intercepts of the thermal expansion lines given in Figure 8 were recorded in Table 1 and plotted against clay loading in all the three directions S1, S2, and S3 as shown in Figure 10. The profile given in Figure 10 may give a glimpse about the contraction or shrinkage behavior of the composites. One can easily see that as clay loading increases to higher values, that 


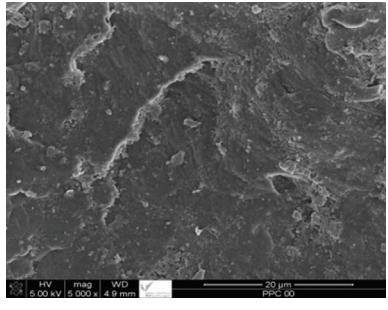

S1

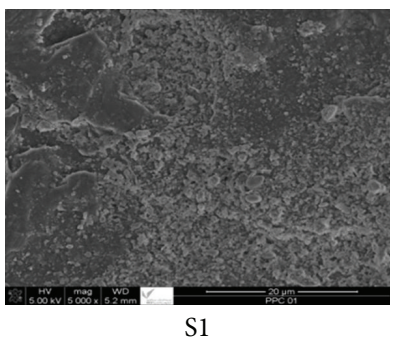

S1
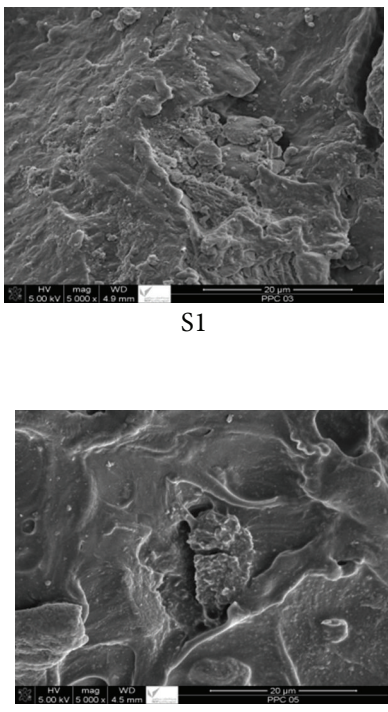

S1

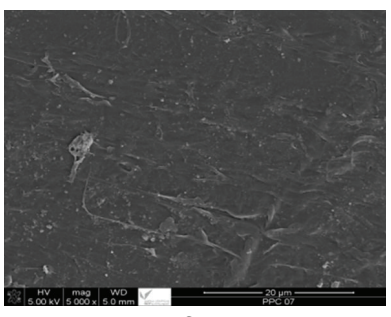

S1

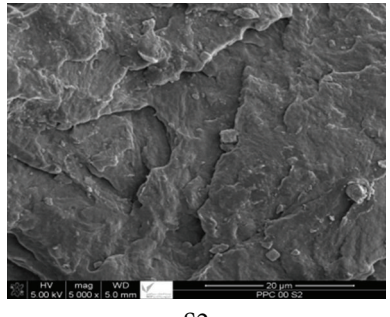

S2

(a)

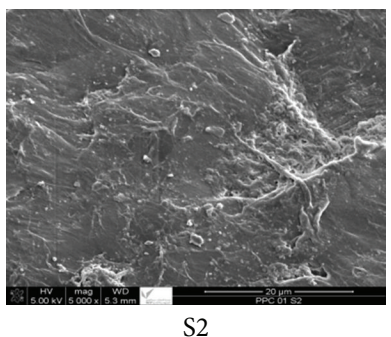

(b)

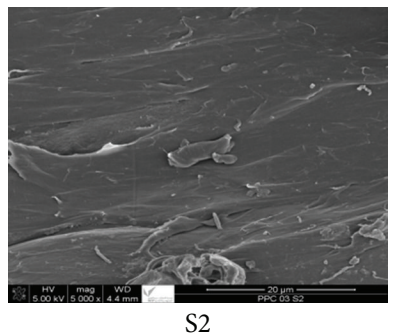

(c)

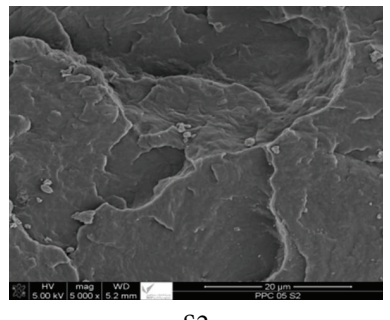

S2

(d)

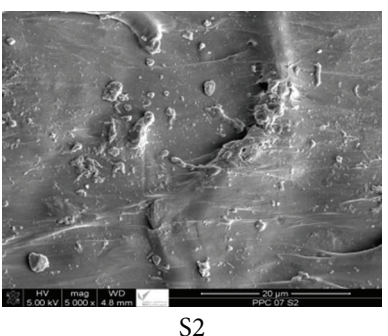

(e)
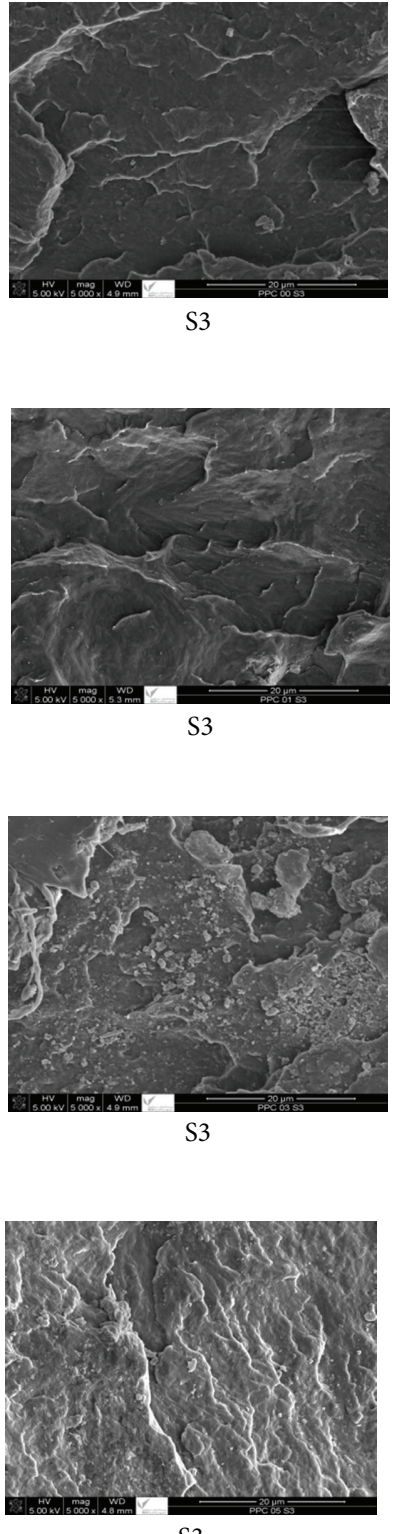

S3

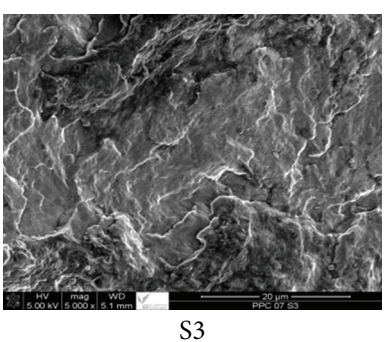

S3

FIGURE 7: SEM micrographs for the fractured surfaces of the compression molding specimens at various clay loadings (wt\%). (a) 0; (b) 1; (c) 3; (d) 5; (e) 7 . 


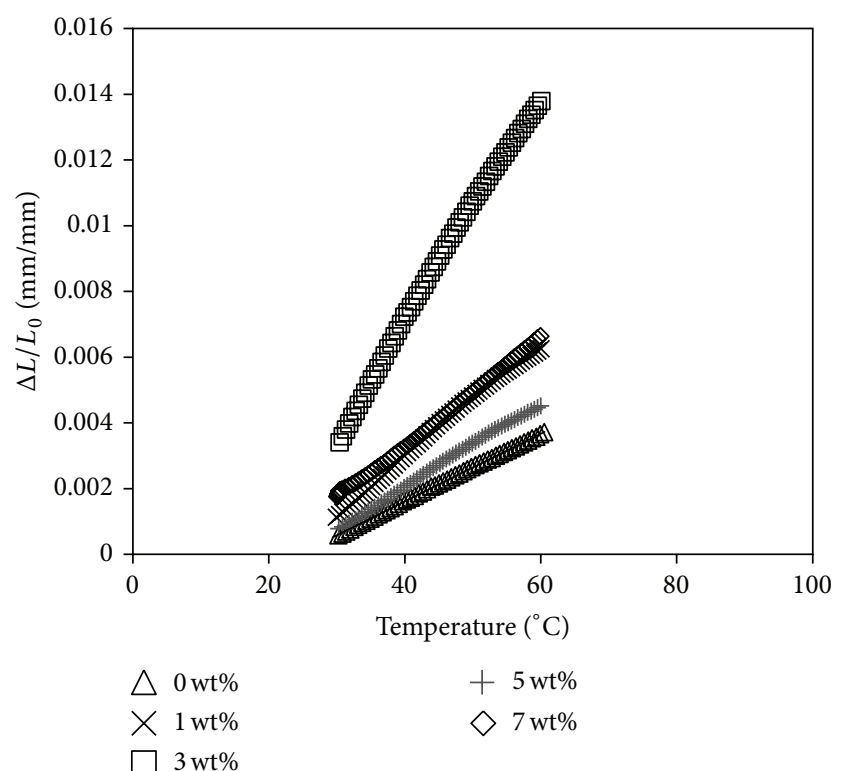

(a)

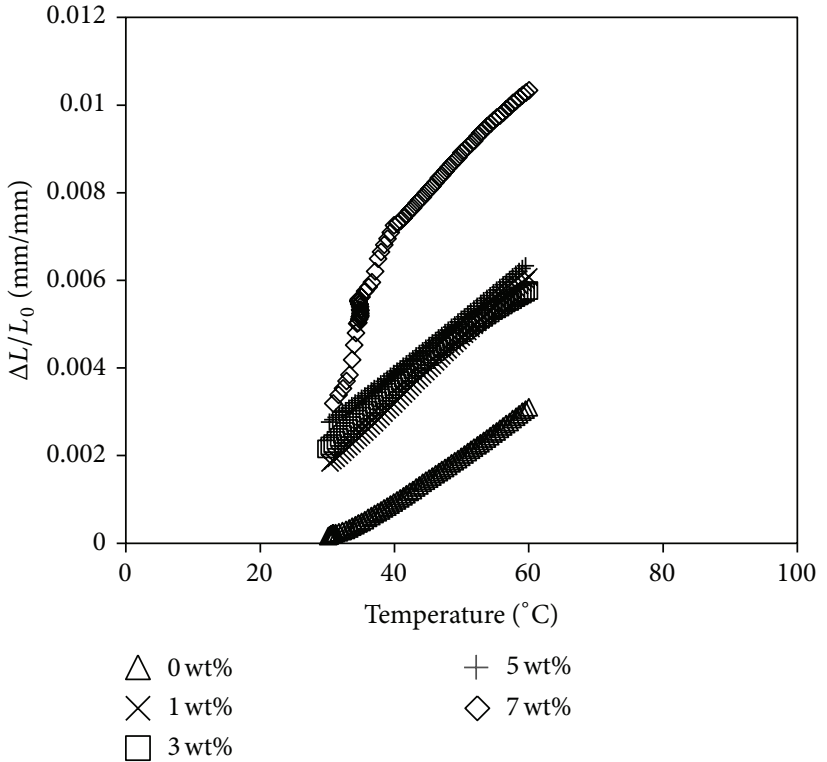

(b)

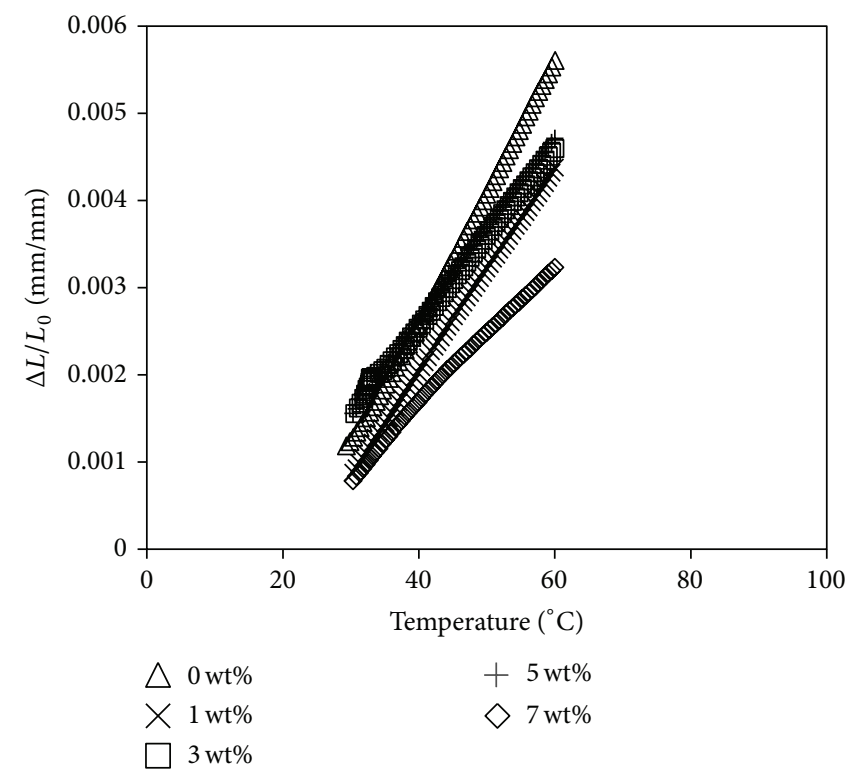

(c)

Figure 8: Change in specimen's length upon heating by TMA. (a) S1; (b) S2; (c) S3.

is, sgreater than $3 \mathrm{wt} \%$, the contraction decreases significantly. This result may be linked with the appearance of compression molding sheets given in Figure 6 where increasing clay loading was seen to reduce their shrinkage or contraction to greater extent. However this is only an observation with no correlation to structure of the prepared composites, and we believe that this aspect requires further investigation.

\section{Conclusions}

The LTEC of the less oriented neat PP prepared by compression molding was seen not to be affected by direction of test whether it was parallel or perpendicular to compression direction. The LTEC of the PP/clay composites was seen to remain unchanged at moderately high clay loading of $5 \mathrm{wt} \%$ regardless of the direction of the surface at which the LTEC was measured. Addition of clay to neat PP was seen to minimize its shrinkage or contraction behavior.

\section{Conflict of Interests}

The authors declare that there is no conflict of interests regarding the publication of this paper. 


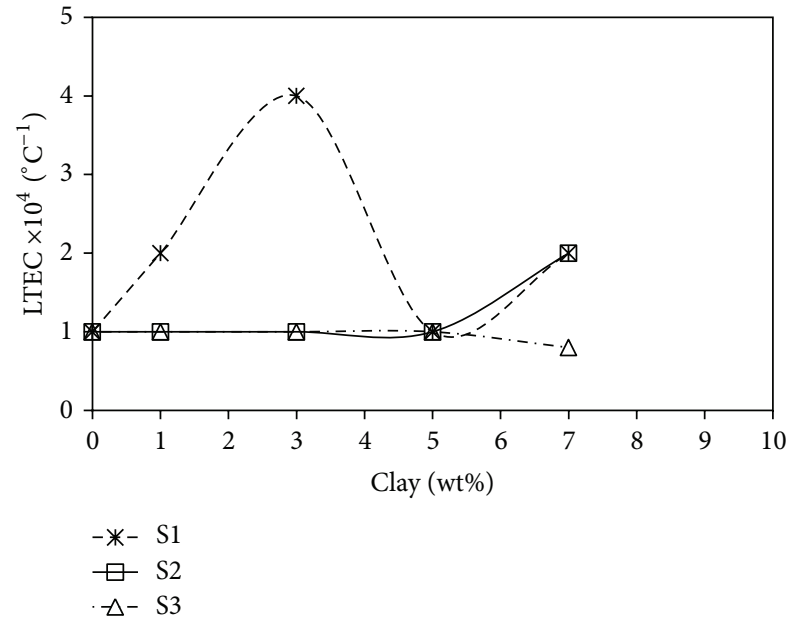

FIGURE 9: LTEC for the PP/clay composites at various clay contents.

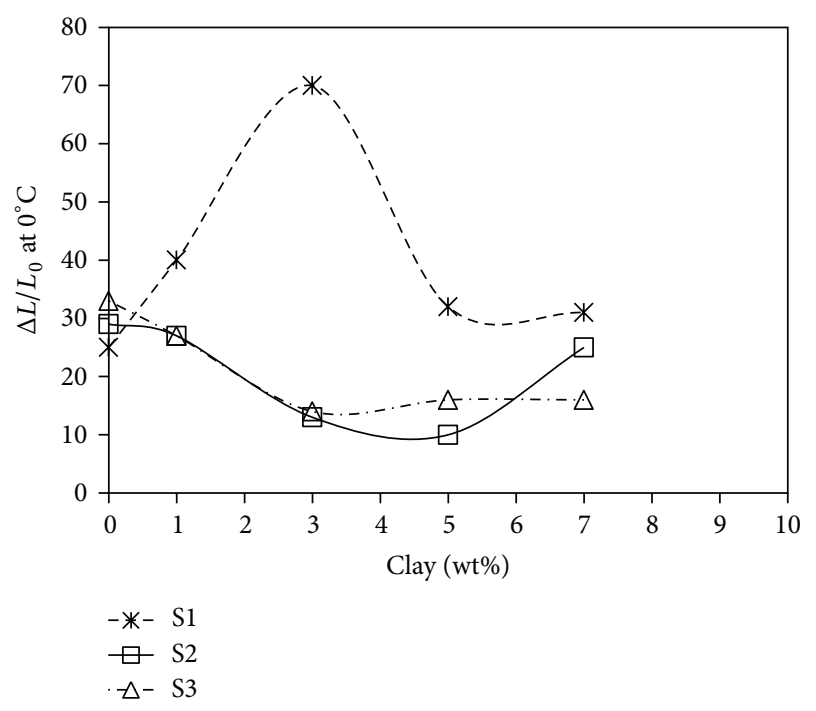

Figure 10: Dimensional specimen's change at $0^{\circ} \mathrm{C}$.

\section{Acknowledgments}

The authors thank King AbdulAziz City for Science and Technology (KSCT) in Saudi Arabia and Izmir Institute of Technology (IZIT) in Turkey for providing required support to carry out this research. Dr. Alsewailem thanks his employer, KACST, for granting him a postdoctoral assistantship during his visit to IZIT.

\section{References}

[1] C. L. Choy, F. C. Chen, and E. L. Ong, "Anistropic thermal expansion of oriented crystalline polymers," Polymer, vol. 20, no. 10, pp. 1191-1198, 1979.

[2] S. A. Jawad, G. A. J. Orchard, and I. M. Ward, "The thermal expansion behaviour of oriented polypropylene," Polymer, vol. 27, no. 8, pp. 1201-1210, 1986.
[3] D. J. Lacks and G. C. Rutledge, "Mechanisms for axial thermal contraction in polymer crystals: polyethylene vs isotactic polypropylene," Chemical Engineering Science, vol. 49, no. 17, pp. 2881-2888, 1994.

[4] M. Ono, J. Washiyama, K. Nakajima, and T. Nishi, "Anisotropic thermal expansion in polypropylene/poly(ethylene-co-octene) binary blends: influence of arrays of elastomer domains," Polymer, vol. 46, no. 13, pp. 4899-4908, 2005.

[5] J. L. Thomason and W. M. Groenewoud, "The influence of fibre length and concentration on the properties of glass fibre reinforced polypropylene: 2 . Thermal properties," Composites Part A, vol. 27, no. 7, pp. 555-565, 1996.

[6] P. Hine, V. Broome, and I. Ward, "The incorporation of carbon nanofibres to enhance the properties of self reinforced, single polymer composites," Polymer, vol. 46, no. 24, pp. 10936-10944, 2005.

[7] K. Kalaitzidou, H. Fukushima, and L. T. Drzal, "Multifunctional polypropylene composites produced by incorporation of exfoliated graphite nanoplatelets," Carbon, vol. 45, no. 7, pp. 14461452, 2007.

[8] H. Krump, A. S. Luyt, and I. Hudec, "Effect of different modified clays on the thermal and physical properties of polypropylenemontmorillonite nanocomposites," Materials Letters, vol. 60, no. 23, pp. 2877-2880, 2006.

[9] H.-S. Lee, P. D. Fasulo, W. R. Rodgers, and D. R. Paul, "TPO based nanocomposites. Part 2. Thermal expansion behavior," Polymer, vol. 47, no. 10, pp. 3528-3539, 2006.

[10] D. H. Kim, P. D. Fasulo, W. R. Rodgers, and D. R. Paul, "Structure and properties of polypropylene-based nanocomposites: effect of PP-g-MA to organoclay ratio," Polymer, vol. 48, pp. 3508-3523, 2007.

[11] D. H. Kim, P. D. Fasulo, W. R. Rodgers, and D. R. Paul, "Effect of the ratio of maleated polypropylene to organoclay on the structure and properties of TPO-based nanocomposites. Part II: thermal expansion behavior," Polymer, vol. 49, no. 10, pp. 2492 2506, 2008. 

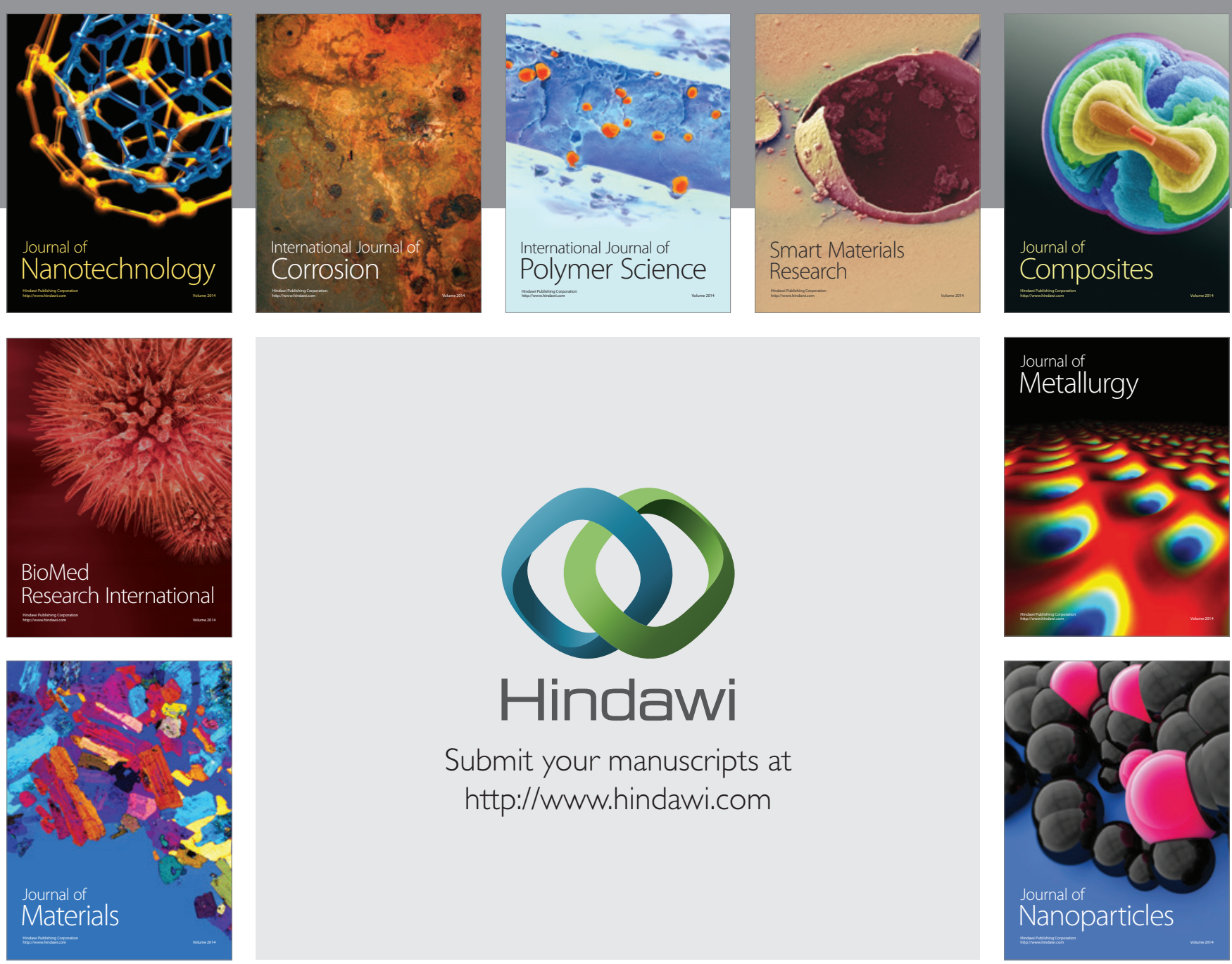

Submit your manuscripts at http://www.hindawi.com
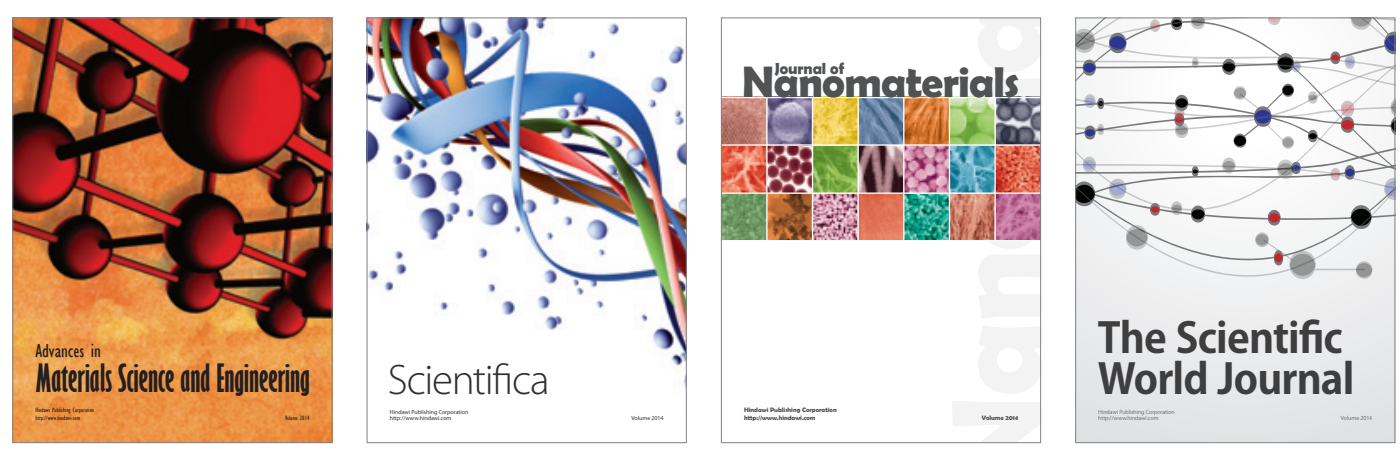

\section{The Scientific World Journal}
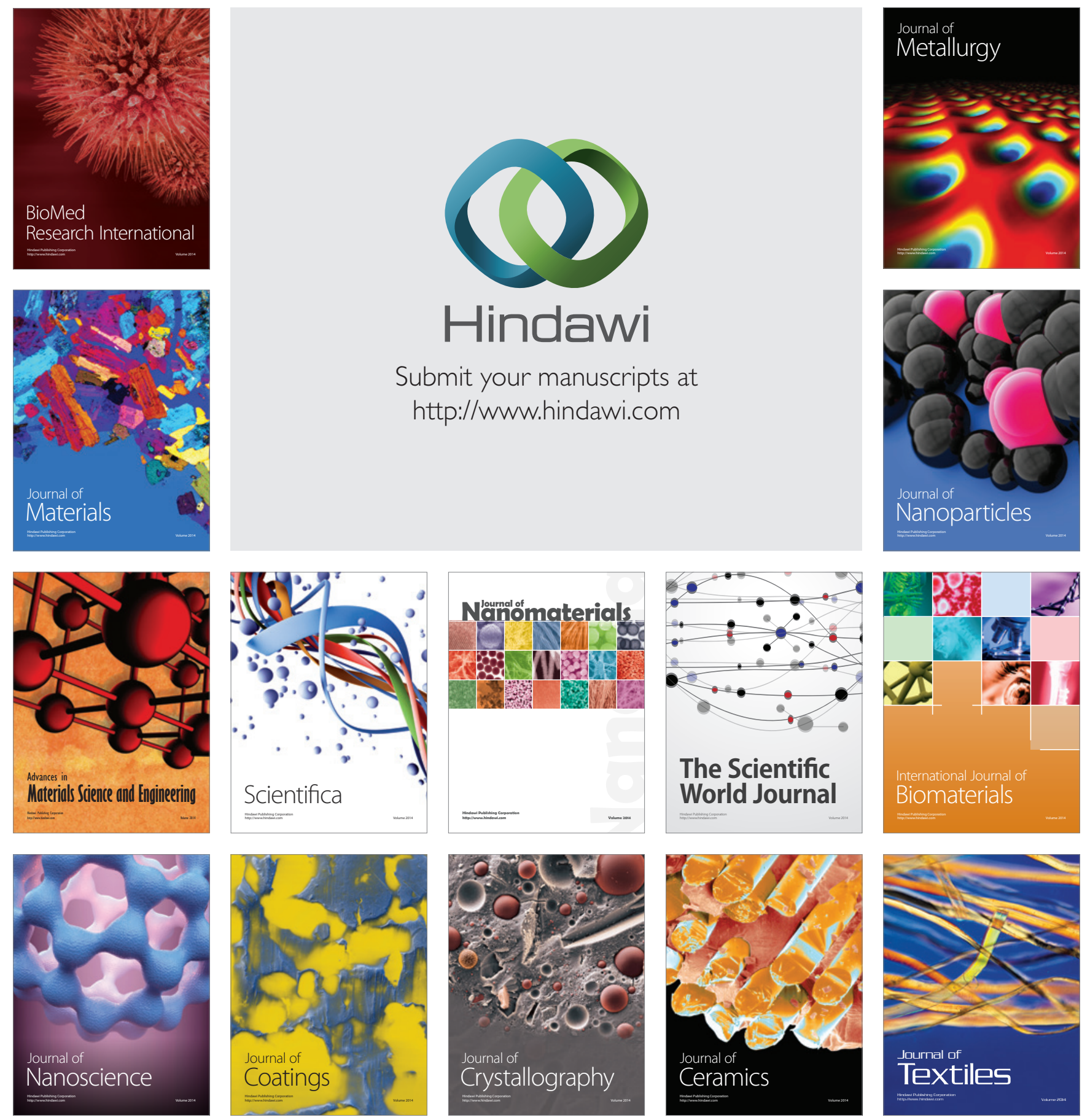